\title{
Remaking Homo: ethical issues on future human enhancement
}

\author{
Arthur Saniotis* \\ ${ }^{*}$ School of Medical Sciences, The University of Adelaide, North Terrace, Adelaide, South Australia 5005, Australia
}

\begin{abstract}
Since prehistory, the genus Homo has used technologies in order to enhance fitness. With the growth of bio-technologies, western medicine is improving the structure and function of the human body beyond its natural state. Bio-technological improvements in the next 50 yr promise further increases in human life span and performance. Notwithstanding the ethical argument encouraging transhumanist technologies, present human societies have yet to come to grips with the possibility of such a future world. This article will discuss future nootropic enhancers and human-animal gene splicing as possible enhancement technologies in relation to their ethical and social implications.
\end{abstract}

KEY WORDS: Evolution · Neural plasticity · Nootropics · Cosmetic neurology · Chimera · Post-human

\section{INTRODUCTION: HUMAN BIOLOGICAL AND CULTURAL PLASTICITY}

Since prehistory the genus Homo has been engaged in various technologies in order to enhance fitness. Tool use increased with $H$. habilis ('tool making man') approximately 2 million years ago (mya). $H$. erectus began to use fire as an enhancing technology over 1 mya, as well as, creating a sophisticated tool kit. The symmetrical axes of $H$. erectus testify to their considerable abstract and coordination skills. Tool use enhanced human cognitive skills and informed hand evolution. Moreover, the advent of fire transformed human society and greatly enhanced early humans' ability to dominate their lifeworld. Fire use also changed human dental and 'masticatory skeleton' since cooking softened food, thereby decreasing chewing (Henneberg 1998, p. 748). Cooking food also changed the chemical composition of food, allowing for better digestion
(Henneberg 1998, p. 748). In addition, during the Pliocene period, there was considerable reduction in the gastrointestinal tract, probably due to the increasing intake of dietary meat (Beals et al. 1984, Henneberg 1998, p. 748).

The human brain's neuroplasticity, which relied on symbolic consciousness, enabled hominins to learn at an exponential rate. By the time of the Upper Paleolithic period, ancestral humans had a remarkable tool kit, art, spirituality, and sophisticated survival skills. These hominins were thoroughly modern in their behaviour. The plethora of prehistoric art found in many European regions indicates spiritual concepts, probably informed by early shamanism (Henneberg \& Saniotis 2009, Saniotis \& Henneberg 2011a). What is evident in ancestral art is a concern to understand the non-human lifeworld. Cultural-based behaviour continued to enhance humans. By the time of the Holocene period (12000 yr ago to present), humans had transformed their mode of production (i.e. to 
agriculturalism and animal husbandry), eventually giving rise to civilisation. Along with these technological changes came ethical and political issues. For example, the agricultural revolution led to sedentism and the need for organised and stratified societies. In addition, the atomic age necessitated various social and political protocols in order to diminish the likelihood of nuclear holocaust.

Throughout human history there has been a drive to engineer new technologies as a way of improving life. Biological and cultural plasticity have informed each other. Since the enlightenment period, scientific developments have improved human life. Over the course of the 20th century, a litany of medical technologies and public health measures dramatically enhanced the life span and life quality of humans. Recent discoveries of human and non-human genomes have expedited human understanding of the integral role of DNA. Furthermore, increasing research in epigenetics is revealing the complex interplay between genes and the environment in health and disease. The current direction of bio-medicine, which began in the late 20th century, has shifted focus from 'saving lives' and averting premature death to improving the structure and function of the human body beyond its natural state (Saniotis \& Henneberg 2011b, p. 562). Bio-technological improvements in the next $50 \mathrm{yr}$ promise further increases in human life span and performance. The potential enhancement in human cognitive and physical performance has been the focus of futurist thinkers such as Ray Kurzweil $(2000,2005)$ Nick Bostrom (2003, 2005) and Ramez Naam (2005) to name a few. These thinkers propose that the 21st century will lead to a revolution in human enhancement technologies, leading to a state whereby humans will become 'post-human'. Post-humanity will have superior cognitive and sensory abilities and greatly expanded life spans. For Kurzweil, future humans will be engineered by nanotechnology. Bostrom (2003) points out that future enhancements will overcome human biological limitations, leading to higher intelligence, health, and emotional sensitivity. In other words, enhanced humans may have a greater capacity to be moral and ethical beings, which will have spill over effects throughout society. As Bostrom (2003, p. 496-497) asserts:

Transhumanism promotes the quest to develop further so that we can explore hitherto inaccessible realms of value. Technological enhancement of human organisms is a means that we ought to pursue to this end. There are limits to how much can be achieved by low-tech means such as education, philosophical contemplation, moral self-scrutiny and other such meth- ods proposed by classical philosophers with perfectionist leanings, including Plato, Aristotle, and Nietzsche, or by means of creating a fairer and better society, as envisioned by social reformists such as Marx or Martin Luther King.

Notwithstanding the ethical argument encouraging transhumanist technologies, present human societies have yet to come to grips with the possibility of such a future world. What would be the wide-ranging ethical, social, and political ramifications of a transhumanist society? While such a question is beyond the scope of this article, I will examine the use of nootropics and transgenic technologies in the future. My aim is to present some ethical arguments stemming from these kinds of human enhancement efforts.

\section{FUTURE NOOTROPIC ENHANCERS: SHORT-CUT TO ENHANCEMENT?}

The term 'nootropic' was first mentioned by Giurgea (1972) and derives from the Greek words 'nous' meaning 'mind' and 'trophos' meaning 'to nourish'. According to archaeological evidence humans have been using nootropic substances since prehistory. Winkelman purports that humans and nootropic substances co-evolved over a long evolutionary period. He further claims that ancestral humans engaged in taking nootropic substances in order to elicit altered states of consciousness (ASC) (Winkelman 2001, p. 339). The early hominin ability to enter an ASC may have expedited brain evolution, leading to shamanistic systems. Ancestral nootropic use would have triggered both serotonergic and dopaminergic activation within the pre-frontal cortex and other cerebral regions heightening religiousbased experiences (Winkelman 2004, p. 199). Extensive use of nootropics may have led to an increased understanding of the mind's cartography, fostering further mind-altering techniques found in shamanistic and traditional societies (Saniotis \& Henneberg 2011c).

While nootropics were a feature in many ancient and medieval societies, their use became expedited during the post-war period. During this time, nootropic substances became increasingly commercialised, leading to their accessibility to the general public. For instance, the 1950s and 1960s saw a proliferation of amphetamine usage. Furthermore, use of synthetic psychotropics such as LSD (lysergic acid diethylamide) and cannabis became a central part of the 'hippie movement' in western cultures. These 
nootropics were widely used for promoting transcendental-type experiences. Their use became a source of reprobation by western governments, which consequently banned their use.

Increasing use of licit and illicit nootropic substances has been a feature of many western and nonwestern societies, leading to unprecedented addiction. For example, approximately 140 million people suffer from alcohol-related disorders (Saniotis 2010), while smoking-related mortality accounts for onetenth of global deaths (Martin 2002). Substance abuse has reached epidemic levels, in the third world particularly, and does not show any sign of abating in the near future.

Currently, first world people are increasingly using various kinds of nootropic enhancers in order to increase 'normal neurocognitive function' (Farah et al. 2004, Malik et al. 2007, Lanni et al. 2008, Saniotis 2009 , p. 32). The use of nootropics to enhance cognition is referred to as 'cosmetic neurology' (Chatterjee 2006). The widespread nature of cosmetic neurology is testified to by the fact that approximately $18 \%$ of American college students are using stimulants such as Methylphenidate and Dextro-Amphetamine as study aids (Babcock \& Byrne 2000, Farah et al. 2004, Arnsten \& Dudley 2005). The use of these nootropics has more or less become normalised for this age group. Various other nootropics are currently being tested for military and non-military purposes such as Modafinil for increasing reaction time and vigilance (Turner et al. 2003, Bostrom \& Sandberg 2006, p. 8), Atomoxetine for boosting arousal (Babcock \& Byrne 2000), and Ritalin for cognitive performance. With advances in neuroscience and pharmacological psychiatry, the range of nootropic enhancers is increasing. Some natural nootropic enahancers such as the Aryuvedic herb Brahmi have been touted as enhancing cognitive performance. Other 'natural' nootropics such as fish oil and lecithin, which may protect the brain from age-related cognitive disorders, are widely used by westerners. Recent interest in the nootropic potential of ethno-botanical plants may offer a new generation of therapeutic drugs in the future. There is also a likelihood of nanobased 'smart drugs' being offered in the near future to health conscious 'baby boomers' and younger generations. While 'smart drugs' are being heavily researched by pharmaceutical companies, there is growing ethical concern about the use of nootropic enhancers. Future nootropic enhancers may be considerably more effective than current nootropics, offering a range of cognitive improvements. While such substances will have far-ranging im- plications for future societies, there are several areas of concern.

\section{ETHICAL AND SOCIAL IMPLICATIONS OF USING NOOTROPICS}

The use of nootropics opens several ethical dilemmas. Firstly, their use, particularly amongst students, may be viewed as a form of cheating. However, the onus on academic achievement as a requirement for upward social mobility is increasingly informing students to use such substances. Genetic research on cognition suggests that approximately $50 \%$ of IQ is inherited (Devlin et al. 2001). Cakic (2009, p. 612) rightly points out that due to the already uneven socioeconomic inequalities operating in many societies, the use of nootropics would probably exacerbate 'educational inequalities'. However, if nootropic use was proven to be a cost-effective means for enhancing various kinds of cognitive performance, they could be used by people who may have cognitive deficits, or made 'accessible to the under privileged' (Cakic 2009, p. 612). For example, a study conducted by Müller et al. (2004) showed a positive effect of Modafinil use on the working memory skills of students (single dose $200 \mathrm{mg}$, given to male and female healthy subjects, age range 20 to $29 \mathrm{yr}$ ) with lower IQs, but with limited improvement on the working memory skills of students with higher IQs (Randall et al. 2005, p. 134). Furthermore, Müller et al. (2004, p. 166) note increasing difficulty in improving cognitive performance on high-performing subjects. In other words, their research indicates an apparent 'ceiling effect' on nootropic use (Randall et al. 2005, p. 138). This poses the question: does optimal or enhanced cognitive functioning come at the expense of other brain functions? These studies may hint at the probable limitations of nootropics as 'global' cognitive enhancers. If this is the case, then it would be better to focus on other ways of enhancing cognition, such as regular exercise, which produces the brain-derived neurotrophic factor (BDNF), which stimulates brain mitochondria for more efficient oxygen delivery (Noakes \& Spedding 2012, p. 296).

My major ethical concerns are cognate to those of Greely et al. (2008, p. 703), who note that currently no government medicinal regulations exist on 'off label' uses of potential enhancement drugs. While many prescription drugs have potential side effects, the potential risks to 'healthy individuals seeking en- 
hancement' may be unacceptable (Greely et al. 2008, p. 703). For this reason Greely et al. (2008) encourage more rigorous evidence-based research into cognitive-enhancing substances in order to evaluate their potential benefits and costs. Such considerations will be even more necessary if and when future nanotech-based nootropic enhancers are produced. Appropriate policies should also discourage the use of cognitive enhancers by students and employees. This is especially the case for children and adolescents who may be coerced into taking them by achievement-orientated parents (Greely et al. 2008, p. 703). A major reason for the prohibition of nootropic enhancer use by children and adolescents is that their brain is undergoing crucial development during these stages. For example, the pre-frontal cortex, nucleus accumbens and amygdala in adolescents are still immature, thereby increasing risk-taking behaviours. These areas regulate decision making, impulse control, problem solving and emotional adjustment (Casey et al. 2008). Research indicates that maturation of the pre-frontal cortex may continue up until $25 \mathrm{yr}$ of age (Walsh 2004). Bearing this in mind, any future research on putative nootropic enhancers should consider the complex neuro-hormonal developmental stages of children and adolescents. Present and future societies need to reassess the kinds of cognitive enhancements which should be given to children and adolescents. Preferably, those with minimum risk of harm. Present-day policy makers need to take into account the ethical and political implications of nootropic enhancers. This is a veritable grey zone which will need monitoring by researchers, pharmaceutical companies and political parties.

\section{HUMAN-ANIMAL GENE SPLICING}

The term 'chimera' in scientific terminology refers to the combination of genetic material between different species in order to create a hybrid. These include human-animal chimeras and animalhuman chimeras. Subsequently, a chimera has the genetic material of 2 or more species. The ability to create chimeras testifies to the fact that all life is related by virtue of DNA, which was inherited by a common distant ancestor during the Achaean Period approximately 3.9 billion years ago. During this period protozoa co-evolved in what Margulis (1993) subscribes to as symbiogenesis, whereby the organelles found in eukaryotes were once independent, but combined in order to enhance sur- vival. These early microbial life forms were chimera-like in a sense, but became highly successful, leading to a plethora of multi-cellular life during the Cambrian Period (542 mya).

The depiction of chimeras was first popularised in H. G. Wells' novel 'The Island of Dr. Moreau' (1896). The story is based on a brilliant but mad scientist who genetically creates animals to have human-like behaviours. The hum-animals have a symbolic-based consciousness similar to humans. The 1997 movie based on the book title has the hum-animals triumphing over their human creators in a soirée of maniacal violence. The movie is a caveat against the excesses of science in violating the boundaries between human and non-human animals. A more recent movie based on the chimeric theme is 'The Rise of the Planet of the Apes' (2011) in which a medical scientist rears a genetically altered chimpanzee named Caesar which develops astonishing humanlike consciousness and behaviours. The movie eventually leads to genetically enhanced simians revolting against their human captors and threatening the dominance of human beings. Again, the movie is a warning of the consequences of genetically deviating from nature.

Movie themes of transgenic creatures are far removed from reality. Transgenic technologies have been in use for nearly 4 decades. The first human-animal splicing of DNA was in 1974 at the Sheng University in China, when a simian virus was inserted into mice embryos (Margawati 2003). This event was a turning point as it paved the way for the pharmacological use of chimeras in treating various human diseases.

Current commercial transgenic uses are based on genetic husbandry of 'pharm' animals (genetically altered animals). Pharm animals have been used by medical science in order to enhance the lives of individuals with various congenital and non-congenital diseases. The therapeutic uses of chimeras include

- Organ harvesting (xenotransplantation) and replacement of somatic parts such as heart valves, collagen tubes and cartilage (Glenn 2004). For example, transgenic pigs reduce graft rejection (Dobson 2007, Bailey 2010, p. 34).

- Animal products such as transgenic milk for the treatment of phenylketonuria (PKU), hereditary emphysema and cystic fibrosis (Margawati 2003).

- Burns, skin and wound healing (Glenn 2004).

- Stem cell research.

- Transgenic animals have assisted in understanding diseases such as cancer, Parkinson's disease, Alzheimer's, and AIDS. 


\section{ETHICAL AND SOCIAL IMPLICATIONS OF USING CHIMERAS}

The use of chimera in medical science has been important in conducting experiments where it is ethically or legally unviable to use human subjects (Knowles 2003). Fortunately, most countries have legislation and regulations for governing the appropriate use of recombinant DNA. While strict policies delineate recombinant technology, new experimental animal research may 'introduce animal welfare concerns' (Knowles 2003, p. 3). For example, while there have been attempts to reduce animal experiments, tests on genetically modified animals are increasing (Ormandy et al. 2009). Even so, current policies must ensure humane treatment of research animals (Knowles 2003).

While few of us would deny the impact of pharm animals in enhancing human life, bio-critics like Jeremy Rifkin are concerned about the 'commodification' of such genetic engineering that is open to wide-ranging patenting. For example, in 1998, Rifkin attempted to patent the 'humanzee' (part human, part chimpanzee chimera) in protest against the potential misuses of recombinant technology (Baylis \& Scott 2006). According to Rifkin, bio-tech companies are free international players with an agenda to privatise human, animal, and plant genomes (King \& Stabinsky 1998, Rifkin 1998). Moreover, Rifkin highlights the potential for pharm companies to become 'biofactories' (Saniotis 2007). The 2006 GTC Biotherapeutics Report noted that sales for Factor VllA for haemophiliacs had reached \$845 million for 2005, with estimated future sales of \$2 billion by 2012 (GTC Biotherapeutics 2006).

Recent public objections to the medical creation of transgenic animals are based on naturalistic and human dignity arguments. Opponents of chimera cite their 'unnaturalness' and the gross manipulation of nature (Kass 1997). This kind of mindset subscribes to the 'natural law' theory which argues for the uniqueness of each species and their right to follow nature's course according to natural determinants (i.e. natural selection and variation) (Crowe 1977). Furthermore, subscribers to human dignity argue that human beings possess a distinct, unique and inalienable quality that is not only absent in non-human animals, but is threatened via transgenic technologies (Robert \& Baylis 2003, Baylis \& Robert 2007). The issue of human blurring is a significant one, especially where the transfer of human tissue into a non-human animal may lead to the emergence of unfamiliar physical or mental behaviours. I am alluding here to where human FOXP2 amino acid substitutions were recently inserted into mouse FOXP2 (Dominguez \& Rakic 2009). This led to increased synaptic plasticity in mouse neural circuits and increased vocalisation (Dominguez \& Rakic 2009. Fortunately, for now at least, such experimentation is prohibited in great apes, possibly because it may further erode the boundaries between humans and simians. Knowles (2003, p. 6) states:

In these cases it is important to be careful that any resulting animal chimeras not develop uniquely human characteristics such that it might lead to the conclusion that some 'degree of humanity' or human dignity has been conferred on the resulting entity.

For Savulescu, there is much merit in creating transgenic humans, as it may become a means of bringing humans closer to non-human animals. Such an awareness may eventually lead to more humane social attitudes towards the non-human world (Barnosky et al. 2011).

For humans, transgenic technologies may lead to sensory and cognitive enhancement, but not for some time. Savulescu argues that combining certain animal traits, such as the long-term memory of elephants or increased night vision of owls, to the human genome would enhance human abilities (Savulescu 2003). Additionally, Savulescu points out that such genetic interventions would be an expression of our humanity, and an extension of Homo faber. Accordingly, he writes (Savulescu 2003, p. 24):

In this regard it is not possible to speak generally about whether such alterations are an expression or threat to humanity. Some radical genetic alterations are an expression of our humanity, while others are not.

Ethical issues need to keep in line with future transgenic developments. Strict regulations and guidelines need to be enforced so as to focus on therapeutic transgenic technologies. In September 2008 the US Food and Drug Administration drafted guidelines for recognising genetically altered animals as pharmaceuticals (Bailey 2010, p. 48). Such a measure was taken because products from transgenic animals have the capacity for affecting body function and structure (Bailey 2010, p. 49).

Any potential for human enhancement via recombinant DNA should be scrutinised by bio-ethicists, scientists, and policy makers, as well as, through public debate. This is especially important due to the possibility of transgenic humans passing their unique human/non-human characteristics on to their progeny, thereby, affecting the human gene 
pool. For this reason future research should examine to what extent tissue from transgenic humans may alter DNA.

\section{CONCLUSIONS}

This article has focussed on nootropics and human-animal gene splicing as possible methods of human enhancement in the near future. Since the dawn of the Pleistocene period the genus Homo has used various technologies in order to enhance fitness. Homo and technology have co-evolved over long evolutionary time. According to transhumanists, future bio-technologies offer an opportunity to transcend the biological limitations of our bodies and become post-human; that is, considerably enhanced beings. Both nootropics and human-human gene splicing may offer novel methods for enhancement. However, these methods are fraught with ethical and social consequences which have hitherto not received sufficient attention from scientists and policy makers. The human species may be considerably affected by future enhancement technologies. For this reason, the creation of new bio-technologies must work in tandem with scientific ethics. The abuse of these technologies may have dire consequences for human evolution.

\section{LITERATURE CITED}

Arnsten AF, Dudley AG (2005) Methylphenidate improves prefrontal cortical cognitive function through $\alpha 2$ adrenoceptor and dopamine D1 receptor actions: relevance to therapeutic effects in Attention Deficit Hyperactivity Disorder. Behav Brain Funct 1:2

Babcock Q, Byrne T (2000) Student perceptions of methylphenidate abuse at a public liberal arts college. J Am Coll Health 49:143-145

Bailey E (2010) Transgenic animals: an interactive qualifying project report. Worcester Polytechnic Institute, Worcester, MA

- Barnosky AD, Nicholas Matzke N, Tomiya S, Wogan GOU and others (2011) Has the Earth's sixth mass extinction already arrived? Nature 471:51-57

Baylis F, Robert JS (2007) Part-human chimeras: worrying the facts, probing the ethics. Am J Bioeth 7:41-45

Baylis F, Scott RJ (2006) Primer on ethics and crossing species boundaries. Available at: www.actionbioscience. org/biotech/baylis_robert.html

Beals KL, Smith CL, Dodd SM (1984) Brain size, cranial morphology, climate and time machines. Curr Anthropol 25: 301-330

> Bostrom N (2003) Human genetic enhancements: a transhumanist perspective. J Value Inq 37:493-506

Bostrom N (2005) In defence of posthuman dignity. Bioethics 19:202-214
Bostrom N, Sandberg A (2006) Cognitive enhancement: methods, ethics, regulatory challenges. The Future of Humanity Institute, Oxford University, Oxford

> Cakic V (2009) Smart drugs for cognitive enhancement: ethical and pragmatic considerations in the era of cosmetic neurology. J Med Ethics 35:611-615

> Casey BJ, Jones RM, Hare TA (2008) The adolescent brain. Ann NY Acad Sci 1124:111-126

> Chatterjee A (2006) The promise and predicament of cosmetic neurology. J Med Ethics 32:110-113

Crowe M (1977) The changing profile of the natural law. Martinus Nijhoff, The Hague

> Devlin B, Daniels M, Roeder K (1997) The heritability of IQ. Nature 388:468-471

> Dobson R (2007) Number of UK patients awaiting a transplant reaches record high. BMJ 334:920-921

> Dominguez MH, Rakic P (2009) The importance of being human. Nature 462:169-170

- Farah MJ, Iles J, Cook-Degan R, Gardner H and others (2004) Neurocognitive enhancement: What can we do and what should we do? Nat Rev Neurosci 5:421-425

> Giurgea C (1972) Pharmacology of integrative activity of the brain. Attempt at nootropic concept in psychopharmacology (Vers une pharmacologie de l'active integrative du cerveau: Tentative du concept nootrope en psychopharmacologie). Actual Pharmacol (Paris) 25:115-156

Glenn LM (2004) Ethical issues in genetic engineering and transgenics. Available at www.actionbioscience.org/ biotech/glenn.html

> Greely H, Sahakian B, Harris J, Kessler RC, Gazzaniga M, Philip Campbell P, Farah MJ (2008) Towards responsible use of cognitive-enhancing drugs by the healthy. Nature 456:702-705

GTC Biotherapeutics (2006) GTC Biotherapeutics reports, 3rd quarter. Financial results. Available at www.business wire.com/news/home/20061102005533/en/GTC-Biotherapeutics-Reports-Quarter-2006-Financial-Results

Henneberg M (1998) Evolution of the human brain. Is bigger better? Clin Exp Pharmacol Physiol 25:745-749

> Henneberg M, Saniotis A (2009) Evolutionary origins of human brain and spirituality. Anthropol Anz 67:427-438

> Kass LR (1997) The wisdom of repugnance. New Repub 216: $17-26$

King J, Stabinsky D (1998) Biotechnology under globalisation: the corporate expropriation of plant, animal and microbial species. Race and class: a journal for black and third world liberation. Available at http://hornacek.coa. edu/dave/Reading/race.class.html

Knowles LP (2003) Ethics of research using hybrids, chimeras and cytoplasmic hybrids. Stem cell network. Available at www.stemcellschool.org/pdf/Ethics-of \%20 Research-Using-Hybrids.pdf

Kurzweil R (2000) The age of spiritual machines: When computers exceed human intelligence. Penguin, New York, NY

Kurzweil R (2005) The singularity is near: when humans transcend biology. Viking, New York, NY

Lanni C, Lenzken SC, Pascale A, Del Vecchio I and others (2008) Cognition enhancers between treating and doping the mind. Pharmacol Res 57:196-213

Malik R, Sangwan A, Saihgal R, Jindal DP, Piplani P (2007) Towards better brain management: nootropics. Curr Med Chem 14:123-131

Margawati ET (2003) Transgenic animals: their benefits to human welfare. Available at www.actionbioscience.org/ biotech/margawati.html 
Margulis L (1993) Origins of species: acquired genomes and individuality. Biosystems 31:121-125

Martin T (2002). Global smoking statistics in 2002. Available at http://quitsmoking.about.com/cs/antismoking/a/ statistics

Müller U, Steffenhagen N, Regenthal R, Bublak P (2004) Effects of modafinil on working memory processes in humans. Psychopharmacology 177:161-9

Naam R (2005) More than human: enhancing the promise of biological enhancement. Broadway, New York, NY

Noakes T, Spedding M (2012) Run for your life. Nature 487: 295-296

> Ormandy EH, Schuppli CA, Weary DM (2009) Worldwide trends in the use of animals in research: the contribution of genetically modified animal models. Altern Lab Anim 37:63-68

Randall DC, Shneerson JM, File SE (2005) Cognitive effects of modafinil in student volunteers may depend on IQ. Pharmacol Biochem Behav 82:133-139

Rifkin J (1998) Future pharming-Genetic engineering of animals. Available at www.highbeam.com/doc/1G120601078.html

Robert JS, Baylis F (2003) Crossing species boundaries. Am J Bioeth 3:1-13

Saniotis A (2007) Social and genomic constructions of chimera. J Futures Stud 11:47-60

Saniotis A (2009) Present and future developments in cognitive enhancement technologies. J Futures Studies 14:27-38

Editorial responsibility: Darryl Macer,

Bangkok, Thailand
Saniotis A (2010) Evolutionary and anthropological approaches towards understanding human need for psychotropic and mood altering substances. J Psychoactive Drugs 42:477-484

Saniotis A, Henneberg M (2011a) Manifestations of mystical experience and evolution of the human brain. Hum Evol 26:61-74

Saniotis A, Henneberg M (2011b) Medicine could be constructing human bodies in the future. Med Hypotheses 77:560-564

Saniotis A, Henneberg M (2011c) Explorations into the biology of emotion and religious experience. Int J Anthropol $26: 25-36$

Savulescu J (2003) Human-animal transgenesis and chimeras might be an expression of our humanity. Am J Bioeth 3:22-25

- Turner DC, Robbins T, Clark L, Aron AR, Dowson J, Sahakian BJ (2003) Cognitive enhancing effects of modafinil in healthy volunteers. Psychopharmacology (Berl) 165:260-269

Walsh D (2004) Why do they act that way? A survival guide to the adolescent brain for you and your teen. Free Press, New York, NY

Winkelman M (2001) Alternative and traditional medicine approaches for substance abuse programs: a shamanic approach. Int J Drug Policy 12:337-351

Winkelman M (2004) Shamanism as the original neurotheology. Zygon 39:193-217

Submitted: July 9, 2012; Accepted: December 5, 2012 Proofs received from author(s): February 17, 2013 